\title{
A virada praxiológica
}

The Praxeological Turn

Le tournant praxéologique

\section{Gabriel Peters}

\section{(2) OpenEdition}

\section{Journals}

Edição electrónica

URL: http://journals.openedition.org/rccs/11308

DOI: $10.4000 /$ rccs. 11308

ISSN: 2182-7435

\section{Editora}

Centro de Estudos Sociais da Universidade de Coimbra

\section{Edição impressa}

Data de publição: 1 dezembro 2020

Paginação: 167-188

ISSN: 0254-1106

\section{Refêrencia eletrónica}

Gabriel Peters, «A virada praxiológica », Revista Crítica de Ciências Sociais [Online], 123 | 2020, posto online no dia 15 dezembro 2020, consultado o 17 dezembro 2020. URL : http:// journals.openedition.org/rccs/11308; DOI : https://doi.org/10.4000/rccs.11308 


\section{GABRIEL PETERS}

\section{A virada praxiológica}

O artigo examina a "virada praxiológica" nas ciências sociais da segunda metade do século xx, virada manifesta em teorias que, a despeito de suas discordâncias quanto a questões diversas, se ancoram todas em uma ontologia processual que toma o mundo social como domínio de práticas. Concentrando-se nas semelhanças, mais do que nas diferenças, entre as variadas vertentes de praxiologia, o artigo oferece uma pintura ideal-típica da virada praxiológica na teoria social. Partindo de suas fontes filosóficas na fenomenologia existencial e na pragmática da linguagem, o texto trata de sete postulados presentes, ainda que sob diferentes roupagens, nas teorias praxiológicas de autores como Giddens, Garfinkel, Taylor, Bourdieu e Latour. Como "guinadas internas" que se combinam na praxiologia, aqueles postulados incluem as viradas existencial, culturalista, habitual, corporal, objetal, intersubjetivista e multidimensional.

Palavras-chave: Anthony Giddens; culturalismo; Pierre Bourdieu; praxiologia; teoria social.

\section{Introdução}

O presente artigo $^{1}$ explora a "virada praxiológica" nas ciências sociais da segunda metade do século $\mathrm{xx}$, virada manifesta em diversas teorias ancoradas em uma ontologia processual que toma o mundo social como domínio de práticas - um enunciado aparentemente anódino, mas prenhe de complexas implicações analíticas. Tal perspectiva praxiológica encontra alguns de seus insights fundacionais já na sociologia clássica, mas ganha seus desenvolvimentos mais sistemáticos na teoria social das últimas décadas. Concentrando-se nas semelhanças, mais do que nas diferenças, entre as variadas vertentes de praxiologia, o artigo oferece uma pintura ideal-típica da virada praxiológica na teoria social. Partindo de suas fontes filosóficas na fenomenologia existencial e na pragmática da linguagem, o texto trata de sete postulados ou "viradas internas" à praxiologia presentes, ainda que sob distintas roupagens, em teorias como o estruturacionismo

${ }_{1}^{1}$ Agradeço a Bianca Freire-Medeiros por seus comentários críticos a uma versão anterior do texto. 
de Giddens, a etnometodologia de Garfinkel, o modelo neo-hermenêutico da ação social de Taylor, a teoria da prática de Bourdieu e a teoria do ator-rede de Latour.

\section{Por que "praxiologia"?}

A muitas léguas deste texto está o projeto quimérico de mapeamento exaustivo das fontes históricas e dos usos influentes da noção de "praxiologia" na filosofia e nas ciências humanas. Em vez disso, o presente artigo se concentra sobre o espaço intelectual da teoria sociológica dos últimos 50 ou 60 anos, atravessado que foi por abordagens como as de Garfinkel, Giddens, Bourdieu e Latour. Tais teorias serão lidas à luz de seu intenso diálogo com contribuições filosóficas oriundas das décadas intermediárias do século xx, como a analítica existencial do Heidegger de Ser e tempo, a fenomenologia carnal de Merleau-Ponty e a pragmática da linguagem do segundo Wittgenstein. $\mathrm{O}$ foco decisivo recai, pois, sobre um conjunto de perspectivas que, na segunda metade do século $\mathrm{xx}$, desenvolveram não apenas uma praxiologia enquanto teoria das práticas sociais, mas, de modo mais ambicioso, um retrato praxiológico da conduta humana e da vida societária como tais - i.e., uma ontologia que identifica as "práticas" como locus fundamental da existência do mundo social, ontologia da qual deriva uma série de diretrizes metodológicas para o estudo empírico desse mundo. Como preâmbulo à caracterização ideal-típica da virada praxiológica proposta mais adiante, vale a pena visitar, sumarissimamente, dois retratos anteriores dessa inflexão na teoria social contemporânea, a saber, aqueles avançados por Schatzki $(1996,1997)$ e Reckwitz (2002).

Como que trilhando na filosofia um caminho similar ao percorrido pelos teóricos sociais voltados à superação da dicotomia entre objetivismo e subjetivismo, o wittgensteiniano Schatzki defende que uma ontologia do social como domínio de práticas escapa às dificuldades encontradas por retratos da vida societária que tomam como seus pontos de partida quer a individualidade, quer a totalidade. Em seu ataque a estes dois conceitos como "pontos de partida sócio-ontológicos", Schatzki (1997: 283) pisa em terreno amplamente conhecido dos leitores de Giddens, Bourdieu e outros líderes do (então) "novo movimento teórico" (Alexander, 1987) nas ciências sociais das décadas de 1970 e 1980 (Peters, 2015). Concebida como instância mediadora, a noção de práticas possibilitaria escapar tanto à redução individualista quanto à reificação coletivista, na medida em que sublinha o caráter socialmente moldado da agência individual sem negar, por outro lado, o caráter ativamente moldado das coletividades humanas. Sendo a prática o locus do encontro entre os agentes socializados, de um lado, e os ambientes 
estruturais legados pela história em que eles estão imersos, de outro, uma ontologia praxiológica reconheceria tanto a constituição dos indivíduos pela sociedade (i.e., o fato de que o contexto social molda profundamente modos individuais de agir, pensar e sentir) quanto a constituição da sociedade pelos individuos (i.e., o fato de que as características estruturais dos contextos sociais são ontologicamente dependentes das práticas históricas de agentes humanos). Como resumiu Giddens (2003: 2), na medida em que "as práticas sociais, ao penetrarem no tempo e no espaço, estão na raiz da constituição do sujeito e do objeto social”, “o domínio básico de estudo das ciências sociais" não seria, para uma lente praxiológica, "a experiência do ator individual nem a existência de qualquer forma de totalidade social, mas as práticas sociais ordenadas no espaço e no tempo". ${ }^{2}$

Reckwitz (2002: 250), por sua vez, situou a "visão de mundo praxiológica" entre as perspectivas "culturalistas" nas ciências sociais. "Culturalistas" seriam abordagens que analisam a relação entre conduta individual e ordem social a partir das "estruturas de significado" ou "esquemas simbólico-cognitivos" pelos quais os agentes dão inteligibilidade ao mundo e nele orientam sua conduta. A praxiologia se diferencia das versões "mentalistas", "textualistas" e "intersubjetivistas" de culturalismo devido, como o termo indica, à centralidade que confere à "prática" na análise do mundo societário. A riqueza heurística de uma ontologia do social como universo de práticas advém, entre outras coisas, de sua capacidade de apreensão combinada das múltiplas dimensões da vida social humana. Na pintura da galáxia praxiológica que esboçarei no presente artigo, um foco peculiar será dado a versões de praxiologia que, como a teoria da estruturação de Giddens ou a teoria da prática de Bourdieu, buscam superar tratamentos dicotômicos daquelas dimensões várias do mundo societário, como corpo/ /mente, material/simbólico e subjetividade/objetividade. Tal leitura da praxiologia como via de transcendência de dicotomias tenazes nas ciências sociais se articula, sem dúvida, à tese reckwitziana de que a novidade maior das teorias praxiológicas consiste nos sentidos inter-relacionados que elas emprestam às noções de "corpo, mente, coisas [ou objetos], conhecimento, discurso, estrutura/processo e agente" (ibidem: 243).

Reckwitz não chega a rastrear as fontes da praxiologia em autores clássicos como o Marx das Teses sobre Feuerbach ou o Simmel analista das "formas de sociação", preferindo sublinhar suas raízes na fenomenologia

${ }^{2}$ Schatzki (1997) não aceita in toto as versões "estruturacionistas" de praxiologia propostas por Giddens e Bourdieu, mas submete ambos os autores a uma "crítica wittgensteiniana", que não analisarei aqui, por falta de espaço. 
existencial delineada por Heidegger e na pragmática da linguagem do segundo Wittgenstein. Ao elencar perspectivas que se avizinham ao seu modelo típico-ideal de "practice theory", Reckwitz menciona, além das já citadas teorias de Giddens e Bourdieu, a teoria "neo-hermenêutica" da ação social de Taylor, o neowittgensteinianismo de Schatzki, a etnometodologia de Garfinkel, a "hermenêutica do sujeito" do último Foucault, a teoria do ator-rede de Latour e a teoria performativista do gênero avançada por Butler. Inevitavelmente, a lista reckwitziana é propensa a ensejar dúvidas tanto sobre o que inclui (e.g., não estaria a teoria butleriana do sexo qua gênero bem mais próxima do que Reckwitz chama de "textualismo"?) quanto sobre o que exclui - e.g., o argumento teórico sobre cultura e historicidade desenvolvido por Sahlins em Ilhas de história (1999), notável por sua semelhança com as praxiologias culturalistas de Giddens e Bourdieu. A lista serve, no entanto, como um bom ponto de partida para o mapeamento - forçosamente esquemático - que vai adiante.

\section{Uma virada, muitas viradas}

O cerne da praxiologia é uma ontologia radicalmente processual do mundo societário. De acordo com essa ontologia, o universo social não pode ser tomado simplesmente como um dado que se impõe aos agentes a partir do exterior, mas tem de ser pensado como resultado contínuo e contingente das práticas daqueles agentes. Versões influentíssimas da praxiologia, como a teoria da estruturação de Giddens e a teoria da prática de Bourdieu, são certamente devedoras de abordagens como a fenomenologia, a etnometodologia e a pragmática da linguagem, todas as quais mostraram que a conduta humana não é mero efeito mecânico de forças coletivas, mas um desempenho habilidoso calcado em complexas competências práticas. Por outro lado, Giddens e Bourdieu também criticaram os extremos de subjetivismo a que foram levadas certas críticas a teorias objetivistas, como o estrutural-funcionalismo de Parsons ou o estruturalismo de Lévi-Strauss. $\mathrm{Na}$ busca de uma captura da relação entre as dimensões objetiva e subjetiva da vida social que escapasse tanto ao objetivismo quanto ao subjetivismo, Bourdieu e Giddens postularam que as próprias intencionalidades e competências que movem as intervenções práticas dos agentes no mundo social são moldadas por sua socialização anterior nos ambientes estruturados desse mesmo mundo (Bourdieu, 1983: 47, 1990: 149-152; Giddens, 1993: 128-129, 2003: 29-33). Mediante essa manobra analítica, teorias praxiológicas de síntese pretendiam incorporar a ênfase sobre competências agênticas, oriunda das críticas microssociológicas ao parsonianismo, mas de um modo que evitasse, ao mesmo tempo, as inclinações ao subjetivismo que limitam 
microssociologias interpretativas, como a fenomenologia, o interacionismo simbólico e a etnometodologia.

Como as praxiologias se desincumbem, então, desse duplo objetivo analítico? No que se segue, tentarei oferecer um retrato ideal-típico da virada praxiológica na teoria social a partir de sete postulados ou "viradas internas" a essa inflexão no pensamento sociocientífico:

1) A virada existencial. Diferentemente do que sugere o modelo de sujeito "desengajado" (Taylor, 1997: 10) que tão influente se tornou na filosofia moderna desde Descartes, a subjetividade humana tem de ser pensada em sua conexão originária e inescapável com o mundo, tomado tanto como ambiente material e interpessoal quanto como rede de significados e símbolos intersubjetivos, os quais medeiam a própria operação das faculdades subjetivas individuais;

2) A virada culturalista. A ordem social, tal como produzida e reproduzida nas práticas dos atores humanos, se ancora em uma ordem simbólico-cognitiva, i.e., na partilha de esquemas simbólicos intersubjetivos, mediante os quais aqueles atores atribuem inteligibilidade aos seus cenários de experiência e produzem respostas práticas a eles;

3) A virada habitual. A orientação subjetiva que o agente sustenta em relação aos seus cenários de ação, desde sempre partilhados com outros sujeitos e objetos, é primordialmente pragmática. Uma vez mais em confronto com o modelo "desengajado" de subjetividade, oriundo da epistemologia moderna, a praxiologia retrata a operação dos "estoques de conhecimento" (Schütz, 1979: 74) do agente humano como tutelada pelos interesses pragmáticos que o motivam a participar do mundo social. Na medida que o conhecimento não é uma função "neutra" da subjetividade, mas uma ferramenta da atividade prática, os saberes que habilitam a conduta humana não envolvem somente representações articuladas no discurso, mas também - e decisivamente - competências tácitas e infradiscursivas;

4) A virada corporal. $O$ corpo dos atores não é somente - nem fundamentalmente - uma representação em sua consciência ou o veículo imediato de seus processos mentais, mas o próprio locus primacial das intenções e habilidades que animam seus engajamentos práticos. Dito de outro modo, o agente humano não apenas tem um corpo; ele $e ́$ um corpo lançado no mundo e, por conseguinte, exposto às suas demandas e condicionamentos;

5) A virada objetal. As relações sociais constituídas e reconstituídas em práticas cotidianas abarcam associações complexas entre humanos e objetos. A participação dessas entidades não humanas na tessitura do 
mundo social envolve seus usos como "ferramentas" por parte dos humanos, mas também produz efeitos para além das intenções que eles "delegam" a elas;";

6) A virada intersubjetivista. A subjetividade individual é capaz de orientar-se no mundo em que está imersa graças à aquisição de instrumentos simbólicos intersubjetivamente partilhados, nela instilados por suas experiências de socialização em determinado cenário sociocultural. Tal tese sobre a moldagem socio-histórica das subjetividades individuais acarreta uma diretriz metodológica, a saber, a ideia de que o percurso heurístico mais apropriado à teoria social não parte da subjetividade individual para daí elucidar a intersubjetividade simbolicamente mediada, como nas "filosofias do sujeito", mas assume o sentido reverso;

7) A virada multidimensional. Os aspectos da conduta humana em sociedade que a reflexão teórica tende a distinguir segundo propósitos analíticos estão, na prática, concretamente entrelaçados: processos mentais e movimentos corpóreos, orientações pragmáticas e operações cognitivas, relações intermentais e intercorporais, etc.

Como costuma ocorrer no mapeamento panorâmico de territórios intelectuais vastos e multifacetados, o presente retrato da "galáxia praxiológica" na teoria social contemporânea se preocupa menos com as diferenças a ela internas do que com o que distingue essa galáxia de outras. Nesse sentido, enquanto a distinção entre visões praxiológicas e não praxiológicas da vida social será aqui estabelecida com exagero ideal-típico, as discrepâncias teóricas internas à galáxia praxiológica, apesar de inegáveis e em diversos casos fundamentais, me interessarão menos. Isto dito, uma vez construído o conceito típico-ideal da galáxia praxiológica, é crucial ter em mente que os diferentes postulados teóricos que a integram se interpenetram como parte de uma mesma pintura global da conduta humana no mundo social.

\section{A virada existencial}

O pressuposto básico da "virada existencial" é a crítica ao irrealismo do modelo de relação entre subjetividade e mundo advindo da "epistemologia mediacional” (Taylor, 2005: 36), perspectiva que, de Descartes via Kant

\footnotetext{
${ }^{3}$ Inflexões neotardianas e neodeleuzianas da praxiologia, como a teoria do ator-rede de Latour (2005), enfatizam, para muito além da "interobjetividade" (Latour, 1996), que as associações compositoras do mundo não incluem apenas humanos e objetos inanimados, mas todo um conjunto heterogêneo de outros actantes que podem abarcar dos micro-organismos às divindades. Precisamente porque tal inflexão ontológica é das mais importantes, discuti-la me levaria demasiado longe nesse artigo, de modo que restringirei meu tratamento das entidades não humanas no mundo social aos objetos materiais.
} 
até Husserl, dominou uma porção significativa da filosofia moderna. Oriundo de preocupações epistêmicas com as fundações do conhecimento, tal modelo apresenta a relação sujeito/objeto segundo um dualismo no qual uma subjetividade "do lado de cá" formula representações "interiores" de um mundo externo "do lado de lá", cuja fidedignidade aparece a ela, pelo menos ab initio, como duvidosa. Ancorados em ancestrais filosóficos comuns como Heidegger, Merleau-Ponty e Wittgenstein, praxiólogos como Taylor e Bourdieu asseveram que tal pintura dualista não captura o entrelaçamento constitutivo, primordial e inescapável da subjetividade com o mundo.

Não precisamos exagerar a influência da teia inteira de reflexões heideggerianas sobre a praxiologia para notar que a crítica a visões dualistas da relação subjetividade/mundo, sobretudo aquelas oriundas da primazia que a filosofia moderna deu à epistemologia, deve muito a um veio central de Ser e tempo (2006 [2002]). Heidegger (ibidem: 280-281) sustentou que o "sum" no "cogito sum" deveria ser compreendido desde sempre como "eu-sou-em-um-mundo". A analítica da existência cotidiana se desdobra em outros pressupostos que, mutatis mutandis, também encontrariam abrigo na praxiologia, a começar por uma reformulação do status do conhecimento. Se o conhecimento não é o empreendimento contemplativista de "um sujeito desmundanizado" (ibidem: 275), mas um "modo ontológico do ser-no-mundo" (ibidem: 107), o mundo a conhecer se revela, não como um conjunto neutro de objetos, mas como um domínio socialmente partilhado de ferramentas e práticas no qual o "ser-ấ" se encontra pragmaticamente engajado. Ao salientar que, "de início, um mero sujeito não 'é' e nunca é dado sem um mundo", Heidegger (ibidem: 172) está afirmando também que ele, "de início, não é [...] um eu isolado sem os outros [...], pois os outros já estão copresentes no ser-no-mundo” . Em suma, o ser-aí (Dasein) é ser-com (Mitsein). Trilhando um caminho que se mostraria interessante para diversos cientistas sociais, Heidegger assevera que encontrar-se, desde sempre, imerso ou "lançado" em um mundo significa ipso facto existir, desde sempre, em um cenário povoado por outros.

\section{A virada culturalista}

Uma das melhores sistematizações da perspectiva praxiológica foi costurada por Reckwitz (2002), autor que apresenta teorias praxiológicas como versões particulares de uma abordagem culturalista (lato sensu) do mundo social. "Culturalistas" seriam quaisquer teorias que acessam a relação entre conduta individual e ordem social a partir dos esquemas simbólico-cognitivos que medeiam entre uma e outra. Nesse sentido, uma visão culturalista apreende as ordens sociais como entrelaçadas às ordens culturais pelas quais 
os atores humanos atribuem inteligibilidade ao mundo, e nele orientam sua conduta. São formas simbólicas adquiridas via socialização que facultam aos atores conferir sentido ao real de maneiras suficientemente partilhadas para todos os propósitos práticos. Eis a razão pela qual uma ordenação social de práticas depende de uma ordenação simbólica de sentidos compartilhados. Os "esquemas de tipificação" (Schütz) pelos quais os agentes humanos definem uma situação social como uma "aula", uma "missa" ou uma "festa", para dar somente um punhado de exemplos, não são meros acessórios às suas condutas em tais situações, mas, ao contrário, fatores graças aos quais suas ações e interações são organizadas em padrões inteligíveis e mais ou menos previsíveis.

Central à praxiologia culturalista, ao mesmo tempo, é o fato de que, sendo a cultura mediação da práxis, a práxis também é mediação da cultura: os sentidos simbólicos partilhados não são apenas atualizados na prática (e.g., quando duas pessoas conversam), mas também adaptados, torcidos e criativamente transformados pelos agentes socializados que deles fazem uso em cenários particulares (e.g., quando falantes produzem enunciados novos ou mesmo introduzem modificações no seu idioma para torná-lo mais funcional a tais ou quais propósitos práticos). Nas versões de praxiologia culturalista de autores como Sahlins, Giddens e Bourdieu, esse insight aparece sobretudo na forma de uma crítica ao objetivismo estruturalista pela via da pragmática da linguagem.

Por um lado, estruturalistas tinham toda a razão em destacar a dependência gerativa das práticas humanas em relação a códigos culturais - por exemplo, para ser contextualmente inteligível, a fala de agentes particulares ancora em associações entre sons e sentidos, "significantes" e "significados", estabelecidas no âmbito da língua como característica estrutural de coletividades inteiras. Por outro lado, praxiólogos rejeitam a tendência de estruturalistas diversos a tomarem a dependência gerativa que as ações têm de estruturas culturais como justificativa para um objetivismo em que as primeiras aparecem como meras execuções das últimas. Por exemplo, se as associações entre som e sentido estabelecidas na língua como estrutura gerativa são condições necessárias da fala, elas estão longe de serem suas condições suficientes. Como revelaram abordagens interpretativas, tais quais a análise conversacional e a pragmática da linguagem, as falas só são possíveis porque os agentes adaptam as regras estruturais da língua, de modo inventivo, aos seus contextos pragmáticos de uso. Nesse sentido, no mesmo passo em que capacitam falas situadas inteligíveis, as estruturas gerativas da língua são "colocadas em risco" (Sahlins, 1999: 182) e alteradas conforme as utilizações pragmáticas inventivas que os falantes fazem 
delas em cenários de comunicação particulares. A famosa tese giddensiana quanto à "dualidade da estrutura" (Giddens, 1993: 128-129, 2003: 29-33), ao enfatizar tal interdependência entre estrutura e ação - da qual a interdependência entre língua e fala é uma instanciação particular $-{ }^{4}$ constitui um entre outros avatares dessa visão em que a cultura é mediação da práxis, mas a práxis é, por seu turno, mediação da cultura. Graças a essa perspectiva, a praxiologia tende a escapar a um hiperculturalismo que "textualiza" o mundo social inteiro e, assim, vê-se destituído dos recursos analíticos para o exame da dialética histórica entre o texto e o "fora do texto" (pace Derrida), i.e., entre cultura e práxis.

\section{A virada habitual}

Ao tratar a subjetividade como "ser-no-mundo", a praxiologia não considera o "no" da expressão heideggeriana como mera indicação de localização, mas o lê como índice de um envolvimento pragmático e existencial do agente com sua realidade circundante de pessoas, atividades, ferramentas e tutti quanti. É graças a um estoque de saberes que podemos abrir caminho em meio a esse ambiente em que nos vemos "lançados" e no qual estamos afetivamente investidos. A orientação fundamentalmente pragmática da subjetividade-no-mundo implica, portanto, a tutela desse conhecimento pelos interesses e propósitos que movem nossas ações cotidianas. Devido a tal lógica do "conhecer para agir", muito daquele estoque de conhecimento não veste a roupagem de uma coleção de representações conscientes, mas, sim, aquela de um "know-how" (Ryle, 2009: 14), "savoir-faire" (Bourdieu) ou "consciência prática" (Giddens, 2003: 47) que capacita nossas condutas cotidianas. $\mathrm{O}$ conhecimento prático não se restringe às crenças substantivas de um "saber que" (e.g., a capacidade de reconhecer um policial pela farda), mas também possui um caráter procedimental (e.g., um senso de como se deve interagir com um policial), provendo aos atores um conjunto de "etnométodos" (Garfinkel, 1967) que os auxiliam a "saber prosseguir" (Wittgenstein, 1958: 59-60) nos contextos sociais em que estão embebidos.

\footnotetext{
${ }^{4}$ Considerações similares se aplicariam a outros exemplos de "dualidade" entre estrutura e ação, como a relação entre "economia monetária" e "transação em moeda". A mais mundana troca econômica entre dois agentes que jamais se viram (e.g., a compra de um café na lanchonete), mediante o uso de um pedaço de papel tomado por um e outro como "dinheiro", só é possível porque ambos pressupõem a existência da economia monetária como uma "ordem virtual" ou propriedade estrutural de um sistema social de que ambos fazem parte (e.g., o Brasil). Ao mesmo tempo, a "economia monetária" como estrutura gerativa só adquire continuidade histórica, passando do estado "virtual" ao "atual", nessas transações levadas a efeito pelos agentes econômicos que a pressupõem (Giddens, 2003).
} 
Eis aqui outro âmbito analítico em que o anticartesianismo infuso na praxiologia, desde suas fontes filosóficas, gera implicações em cascata. Ao privilegiar uma noção intelectualista ou "escolástica", diria Bourdieu, do conhecimento como rede de representações articuladas no discurso, boa parte da filosofia e da ciência social modernas terminou por fazer vista grossa à vastidão e à complexidade operacional do saber tácito, prático, não discursivo que é simplesmente indispensável ao "ser-no-mundo" humano. Representantes da teoria social praxiológica não foram, é evidente, os únicos a explorar os modos de formação e operação de orientações e competências habituais na conduta humana. Não sendo possível aqui um tratamento detalhado do tema, pode-se sugerir que, do ângulo teórico, a principal divergência nos retratos da dimensão habitual da vida humana opõe autores mais inclinados a apresentá-la como repetição impensada e automática (e.g., o modelo weberiano da "ação tradicional", pelo menos como tipo ideal) a autores que dão destaque ao seu feitio adaptativo e mesmo criativo. A tendência partilhada entre os membros da galáxia praxiológica é, sem dúvida, mais próxima à segunda posição citada, i.e., a que concebe disposições habituais como capacidades relativamente flexíveis e inventivas de adaptação a circunstâncias mutáveis, não como mecanismos automáticos de mera repetição do passado no presente. O próprio Bourdieu (2009), para dar somente um exemplo, afirmou que seu uso da noção de habitus - grafada no original latino pelo qual Tomás de Aquino traduziu a bexis de Aristóteles - pretendia sublinhar que as disposições práticas do agente socializado não são simples comportamentos reflexos, mas se encontram dotadas de uma capacidade relativamente criativa, que faculta sua adaptação a uma variedade de situações sociais.

\section{A virada corporal}

A presença frequente de ilustrações oriundas do esporte nas caracterizações praxiológicas da conduta humana (e.g., Bourdieu, 1990: 23) não se deve somente à nitidez com que o "senso prático" aparece como motor subjetivo primordial das ações esportivas. Tais ilustrações patenteiam outros dois traços centrais na pintura praxiológica da ação, ambos entrelaçados à importância do conhecimento tácito na produção das práticas: a) as competências cognitivas e práticas do agente são pragmaticamente tuteladas, i.e., funcionam a serviço dos interesses e propósitos que o impulsionam a intervir no mundo social; b) várias das disposições práticas que capacitam a conduta humana são de caráter corpóreo, resultando dos diversos condicionamentos adquiridos mediante experiências de socialização pelas quais aprendemos não somente a usarmos nossos corpos, mas, de modo mais radical, a sermos corpos de tais ou quais maneiras. 
A funda sedimentação de experiências socializadoras no corpo é parte do que move autores como Reckwitz e Bourdieu a sustentar, contra a afirmação algo frouxa de que os seres humanos têm corpos, a tese mais forte de que eles são corpos. Para o primeiro, "quando aprendemos uma prática, aprendemos a ser corpos de uma certa maneira (e isto significa mais do que "usar nossos corpos')" (Reckwitz, 2002: 251). "O que é aprendido pelo corpo”, diz por sua vez Bourdieu, "não é algo que se tem", mas "algo que se é" (Bourdieu, 2009: 120). Como um conjunto socialmente adquirido de disposições de conduta, um habitus designa não somente estruturas mentais de percepção do real, como também "maneiras de ser corpo" que encarnam, "carnificam" ou somatizam o social no indivíduo a partir de suas experiências situadas. Assim, é porque "o corpo está no mundo social", inevitavelmente suscetível às suas influências, que "o mundo social está no corpo" (Bourdieu, 1989: 185), historicamente depositado em organismos socializados na forma de disposições a agir e a padecer como corpo de tais ou quais formas. ${ }^{5}$

A artilharia retórica mobilizada nas críticas de Bourdieu ao esquecimento intelectualista do corpo em teorias da ação as mais diversas - tanto na filosofia quanto nas ciências sociais - é tão intensa que chega às beiras de um fisicalismo, i.e., de uma redução da agência in toto a operações corpóreas (e.g., Bourdieu, 2009: 108-132). Não obstante, se lidos contra o pano de fundo de sua obra mais ampla, na qual o babitus também é frequentemente descrito como imbuído de "estruturas" e "esquemas" mentais, aqueles exageros retóricos não devem ocultar o essencial em sua concepção do relacionamento mente/ /corpo: a superação de visões dualistas. Em sintonia com a oitava tese de Marx sobre Feuerbach, na qual se assevera que "toda a vida social é essencialmente prática" (Marx, 2000: 113), Bourdieu formulou não apenas uma teoria das práticas sociais, mas uma teoria do social como prática ou, dito de outro modo, uma teoria da prática como o modo fundamental de existência do social - em suma, uma praxiologia. Como empresa de superação de umas tantas dicotomias que atravessaram as ciências sociais no século $\mathrm{Xx}$, a teoria bourdieusiana do social, como os demais avatares da praxiologia, pretende apreender o domínio da prática como o locus ontológico mesmo em que se entrelaçam dimensões da ação humana e do mundo societário comumente tratadas de modo dualista: subjetividade e objetividade, individual e social, material e simbólico, etc.

\footnotetext{
${ }^{5} \mathrm{O}$ acento sobre influências socializadoras que são tanto da ordem do agir (i.e., como o corpo intervém no mundo) quanto do padecer (i.e., como o corpo vivencia as influências que o mundo lhe impõe) é um dos motivos pelos quais metáforas do social "sedimentado" ou "depositado" no corpo adquirem alta valia heurística. "Sedimentações" e "depósitos" deixados no corpo pela trajetória experiencial não são somente competências e "técnicas" corporais ativas (Mauss, 2003: 401), mas também apresentam uma contraparte passiva: nossa afetabilidade carnal pelo tempo vivencial acumulado (Merleau-Ponty, 2002: 557).
} 


\section{A virada objetal}

A ideia de que as práticas sociais comportam utilizações informadas e treinadas de artefatos físicos diversos é anódina à primeira vista, mas termina por se desdobrar em uma série tremendamente complexa de consequências analíticas. Heideggerianamente tomados não como coisas materiais "subsistentes" (vorbanden) que se oferecem à contemplação teórica, mas como ferramentas ou "instrumentos" (Zeug) que encontramos "disponíveis" (zubanden) em nossas ocupações práticas, os artefatos físicos podem ser compreendidos como materializações ou objetivações de propósitos do "espírito" humano (Vandenberghe, 2010: 127). Se tal insight está no coração de visões "antropomórficas" da técnica como "extensão" das aspirações e capacidades humanas (McLuhan), urge complementá-las com perspectivas "tecnomórficas" voltadas à demonstração de como os artefatos técnicos, criados para servir aos propósitos humanos, influenciam decisivamente, por seu turno, as maneiras de agir, pensar e sentir do anthropos. O caminho que considero mais fecundo no exame do relacionamento humano com a técnica reconhece uma dialética entre criador e criatura. A dialética histórica em que os artefatos técnicos ampliam as capacidades humanas de intervenção sobre o mundo, mas também passam a moldar historicamente, por seu turno, os modos humanos de existência, proscreve dois unilateralismos em uma só manobra analítica: o instrumentalismo tecnológico, atento às tecnologias como ferramentas práticas dos seres humanos, mas não aos efeitos que tais tecnologias exercem sobre os seus usuários, efeitos evidentes em fenômenos como a historicidade da experiência perceptual (e.g., como sentidos tais quais a visão e o olfato são distintamente ativados a depender da abundância ou ausência de luz elétrica em seus ambientes físicos); o determinismo tecnológico que, ao contrário, toma a evolução da técnica como uma força autônoma em relação às intenções, usos e significados que seus usuários humanos a ela emprestam.

Reconhecer as complexas associações entre humanos e objetos evidencia quão restritiva é a redução da noção de "relações sociais" a intercâmbios entre seres humanos. Tal redução não leva suficientemente a sério: a) os papéis instrumentais dos objetos nas práticas de constituição, reconstituição e transformação da sociedade; b) os modos pelos quais os objetos utilizados pelos atores humanos no mundo social influenciam, por seu turno, as formas de agir, pensar e sentir desses atores; c) finalmente, os efeitos que os objetos geram na vida societária para além da agência e dos propósitos a eles "delegados" pelo ser humano (Latour, 1996: 237). Ao coligir exemplares proeminentes de teoria social praxiológica, Reckwitz (2002: 243-244) não tem maiores embaraços em reunir na mesma lista 
a praxiologia estrutural de Bourdieu e a teoria do ator-rede de Latour. Um dos maiores trunfos da abordagem tecida pelo segundo, sob tantos aspectos em direta oposição ao pensamento do primeiro, consistiu em elaborar as consequências analíticas do reconhecimento da participação dos objetos na constituição do mundo social. ${ }^{6}$

Não há espaço aqui para um exame das continuidades e descontinuidades que a perspectiva latouriana apresenta em relação a tentativas anteriores de tomar, como ele diz em esperta inversão da fórmula durkheimiana, as "coisas como fatos sociais" (Latour, 1996: 240). Por um lado, pesquisadores da vida social concreta certamente já haviam atinado com o fato de que a vida social humana é incompreensível se se faz abstração de suas inter-relações com as coisas, as quais são, nesse sentido, coprodutoras da realidade societária: "camaradas, colegas, parceiros, cúmplices ou associados na tessitura da vida social" (ibidem: 235). Por outro lado, Latour tem farpas diversas a dirigir a esforços prévios de apreensão de como os objetos operam na existência em sociedade. Sua insistência no papel material dos objetos na (re)produção do mundo social fustiga, em um flanco, o "idealismo" de perspectivas que reduzem tais objetos a meras representações mentais na subjetividade individual ou a meros significados no discurso público (como se, digamos, a efetividade prática de um muro alto como obstáculo físico não fosse além do fato de ele "representar" um obstáculo). No outro flanco, Latour também é crítico daquelas abordagens que, no mínimo desde Heidegger, teorizam os objetos como ferramentas de intervenção humana sobre o real. De um modo um tanto simplificador a meu ver, o autor francês acusa luminares dessa visão de ignorarem que os efeitos exercidos pelos objetos na vida social ultrapassam em muito os propósitos a eles delegados pelos seres humanos. Como acontecia na própria filosofia marxiana, a afirmação de que os artefatos materiais substanciem propósitos humanos é compatível, a meu ver, com a possibilidade histórica de que essas criações ganhem autonomia frente aos seus criadores e retroajam sobre eles. De modo similar, corrigir sensatamente a redução idealista dos objetos a representações mentais ou significados discursivos não significa recair, por força, na negligência quanto aos significados, representações e jogos de linguagem em função dos quais esses objetos podem ser "agenciados" de diferentes formas (Vandenberghe, 2010: 129-130, 170-171). A atenção à dimensão simbólica dos objetos é

\footnotetext{
${ }^{6} \mathrm{Na}$ verdade, não apenas dos objetos inanimados, mas de todo um espectro de "actantes" ontologicamente heterogêneos, cujas associações rizomáticas comporiam a socialidade para além de quaisquer cisões entre natureza e cultura. Eis um ponto em que o que há de praxiologia em Latour dá lugar a uma orientação analítica mais bem descrita como uma virada "pós-humanista", cujo tratamento requereria outro artigo.
} 
crucial à compreensão da variedade social e histórica das modalidades de associação e "colaboração" entre humanos e coisas (e.g., uma "mesma" lança operando como instrumento de caça de um indígena e, anos depois, como objeto de decoração na casa de um antropólogo). Isto não precisa resultar, digamos uma vez mais, em fazer vista grossa ao fato de que as consequências produzidas pelos objetos "excedem" (Latour, 1996: 237) cronicamente as intencionalidades neles projetadas pelos seus agenciamentos humanos. ${ }^{7}$

\section{A virada intersubjetivista}

A precedência histórico-biográfica do "público" sobre o "privado", da intersubjetividade simbolicamente mediada sobre a subjetividade individual, é uma tese que Reckwitz encontra nas duas fontes filosóficas primordiais da praxiologia: o "jovem" Hedeigger da analítica da existência cotidiana e o "maduro" Wittgenstein da pragmática da linguagem. Se esquadrinharmos versões de praxiologia mais ecléticas quanto ao seu aparato conceitual, como a teoria da estruturação de Giddens e a teoria da prática de Bourdieu, depararemos com uma série de outros influxos de crítica à "filosofia da consciência" (e.g., os ataques do estruturalismo lévi-straussiano às ilusões da autoconsciência e ao sujeito [neo]cartesiano, o "menino mimado" da filosofia ocidental). Grosso modo, o que é central às versões praxiológicas da crítica à "filosofia do sujeito" consiste na tese de que as operações mais básicas da subjetividade individual são permeadas por instrumentos simbólicos intersubjetivamente partilhados, nela inculcados por experiências socializadoras em tais ou quais "formas de vida" socioculturais. Tal tese substantiva sobre a moldagem da subjetividade individual pela intersubjetividade simbolicamente mediada desemboca em uma diretriz metodológica: o percurso analítico mais adequado à teoria social não é aquele que parte do sujeito individual para pensar a constituição da intersubjetividade, mas, ao contrário, aquele que parte da intersubjetividade para pensar as propriedades do sujeito individual.

\footnotetext{
${ }^{7} \mathrm{O}$ assentimento às afirmações delineadas acima não impede uma montanha de outras controvérsias teóricas quanto às suas implicações ontológico-metafísicas. Um exemplo prosaico indica esse caminho do mais ao menos consensual. Se uso uma calculadora para multiplicar 239 por 35 , em vez de recorrer apenas à minha própria massa cinzenta, faz sentido dizer que minha performance algébrica resultou de minha colaboração com a máquina. Igualmente aceito será o fato de que colaborações com artefatos técnicos influenciam a própria operação das minhas faculdades cognitivas - por exemplo, minha mente aprende a se preocupar muito mais com seu know-bow no uso da máquina do que com sua capacidade de realizar contas de cabeça. Mas aqui começam os debates. Se a multiplicação foi realizada pela "associação sociotécnica" ou "sistema cognitivo" formado por mim e pela calculadora, faz sentido continuar a trabalhar com uma concepção estritamente "intracraniana" de mente, em vez de reconhecer o seu caráter "estendido" ou "distribuído" pelo meu ambiente circundante? Se a máquina foi indispensável à operação matemática, faz sentido dizer que ela "agiu" e "age", assim como eu? Sim? Não? Por quê?
} 
Os indivíduos humanos produzem significados, não a partir de teias de significação de sua própria escolha, mas sim no bojo daquelas que, mediante sua socialização simbólica, foram a eles "legadas e transmitidas do passado" (Marx). Isto dito, abordagens praxiológicas são igualmente críticas de perspectivas que, partindo do reconhecimento sensato do caráter simbolicamente moldado da subjetividade individual, descambam para a dissolução objetivista do sujeito em estruturas simbólicas impessoais e anônimas. Eis por que tanto a teoria da estruturação de Giddens quanto a teoria da prática de Bourdieu desenvolvem uma crítica imanente do estruturalismo, reconhecendo a precedência ontogenética da intersubjetividade simbolicamente mediada sobre a subjetividade individual, sem recair no comum pecado estruturalista e pós-estruturalista de supor que as faculdades subjetivas do agente humano evaporam "em um universo vazio de sinais" (Giddens, 2003: XXIV). Como outrora as notícias prematuras sobre a morte de Mark Twain, os rumores sobre a morte do sujeito na teoria social e na filosofia foram altamente exagerados. Na maior parte das abordagens praxiológicas, a crítica à filosofia da consciência é, assim, um momento na reconstrução do conceito de "sujeito" (ou, pelo menos, de "agente"), não de sua unilateral desconstrução.

\section{A virada multidimensional}

Inspirado pela partitura da ópera wagneriana Tristão e Isolda, Weber vislumbrou um modo de escrita sociológica que, como a música de Wagner, pudesse escapar à apresentação serial de ideias, substituindo-a pela expressão simultânea: "Essa é a técnica de escritura que me faz falta. Com ela à minha disposição, eu poderia [...] dizer muitas coisas separadamente, uma ao lado da outra, mas simultaneamente" (apud Cohn, 1979: 3). O acento praxiológico sobre o entrelaçamento concreto de aspectos da conduta humana e da vida social, costumeiramente distinguidos segundo propósitos analíticos, quando não submetidos a tratamentos polarizados, muito se beneficiaria também daquela "técnica de escritura" outrora desejada por Weber. Nesse sentido, ao elencar uma "virada multidimensional" juntamente com as demais "viradas internas" à praxiologia (existencial, culturalista, habitual, corporal, objetal e intersubjetivista), quero sublinhar que é a interpenetração dessas orientações analíticas (ou viradas internas) em uma abordagem integrada o que define a "virada praxiológica" como um todo mais amplo.

Devido à falta de espaço, diversas implicações teórico-metodológicas resultantes desse entrecruzamento de viradas internas à praxiologia não podem ser detalhadamente exploradas aqui. Cabem, no entanto, algumas ilustrações rápidas de como as teses acima elencadas podem ser interpretadas 
nos termos de tal entrecruzamento. Quando a virada corporal se combina à virada existencial, por exemplo, o vínculo originário e constitutivo entre subjetividade e mundo é tomado como extensível à dimensão corpórea. Essa interpenetração das viradas existencial e corporal pode ser articulada, por seu turno, a lições da virada intersubjetivista quanto ao caráter socialmente moldado da subjetividade individual, bem como à ênfase da virada habitual sobre o feitio tácito das disposições de conduta adquiridas via socialização. Um dos resultados analíticos desse entrecruzamento de múltiplas viradas é uma teoria praxiológica do agente como "corpo socializado" - pressuposta, por exemplo, no conceito merleau-pontyiano de "esquema corporal" (Merleau-Ponty, 2002: 143) ou, com veio sociológico mais radical, na noção bourdieusiana de habitus (Bourdieu, 2009). Em argumento que ata implicitamente as viradas corporal e habitual à virada objetal, Merleau-Ponty (2002: 198) nota que a internalização, em nossos próprios esquemas corporais, dos contextos mundanos em que operamos encontra seus exemplos mais nítidos nos usos competentes de artefatos técnicos. Nos casos, digamos, da ciclista com sua bicicleta, da pianista com seu piano ou da escritora com seu teclado, o agente mergulhado na prática não vivencia suas ferramentas técnicas como objetos dele desconectados, mas, ao contrário, os experimenta como partes de um mesmo corpo "estendido", engajado em uma só performance.

Se o "conhecimento pelo corpo" oriundo da experiência socializadora não se restringe à interação com entidades inanimadas, ele abarca também todo o estoque de saberes práticos que nos habilitam a atuar como corpos animados entre outros corpos animados. Nesse sentido, a ordenação das relações humanas depende também de modos socializados de intercorporeidade, ou seja, de ser corpo entre corpos - por exemplo, como equilibrar proximidade e distância na interação face a face, como se valer de gestos e fisionomias para exprimir aprovação ou desaprovação a outros, como manifestar "sintonia" com as "frequências emocionais" ou "atmosferas afetivas" de certos contextos interacionais (a atmosfera grave de um funeral ou a atmosfera lúdica de uma festa, digamos $)^{8}$ e assim por diante.

\footnotetext{
${ }^{8}$ Como indica a menção de "atmosferas afetivas" entre os ingredientes de situações sociais, padrões de intercorporeidade se conectam a padrões de interafetividade. Um foco sobre a dimensão interafetiva das relações intersubjetivas serve de base, de um lado, à crítica das comuns reduções intelectualistas da intersubjetividade a relações intermentais (quando não somente intercognitivas), assim como, de outro lado, à rejeição de abordagens dos afetos que negligenciam sua dimensão social e intersubjetiva. Isto dito, embora sugestões para uma teoria da interafetividade possam ser extraídas de abordagens praxiológicas, assim como de algumas de suas fontes intelectuais - e.g., o tratamento dos "estados de humor" na fenomenologia existencial de Heidegger (2006: 188-194 -, sua presença na galáxia praxiológica é insuficiente, creio eu, para justificar a inclusão de uma "virada afetiva" entre as guinadas internas aqui listadas como constitutivas da praxiologia.
} 
A despeito da exposição serial feita acima os teoremas centrais à virada praxiológica (a subjetividade existe no mundo; é orientada para agir; é corpo; existe com outros, etc.) devem, portanto, ser compreendidos como aspectos inter-relacionados de uma pintura sincrônica da existência humana em sociedade. Conferindo centralidade às versões de praxiologia associadas a "abordagens de síntese" na teoria social, o presente artigo procurou mostrar como a prática é apreendida, em tais abordagens, como o locus ontológico daquelas inter-relações, tornando-se, por conseguinte, referência analítica básica para a superação de teimosas dicotomias nas ciências sociais. Para repisar um exemplo: ao delinear uma visão não dualista da relação mente/ /corpo, a praxiologia se afasta das concepções intelectualistas de ação que veem o corpo do agente como mero veículo de suas intenções mentais (i.e., como se nossos corpos sempre obedecessem aos propósitos de nossas mentes com máxima proficiência e sem qualquer recalcitrância). Aquele antidualismo rechaça igualmente, por outro lado, as visões fisicalistas da ação corpórea que deixam de lado o caráter inteligente, criativo, versátil e improvisativo dos saberes encarnados no corpo socializado (i.e., como acontece em certas versões de comportamentalismo que tratam do aprendizado corpóreo em termos de associações fixas e atomizadas do tipo estímulo/ /resposta). Outra ilustração: ao conceberem estruturas sociais como condições gerativas da ação, mas também como dependentes, na sua continuidade histórica, das ações que elas possibilitam, praxiologias como as de Giddens e Bourdieu se afastam dos objetivismos que pensam estruturas e sistemas quer como padrões formais arrancados à história (e.g., Lévi-Strauss), quer como forças autopropelidas que tratam os agentes como meros veículos ou "suportes" delas (e.g., no último Parsons ou em certo Althusser). Por outro lado, Giddens e Bourdieu também rejeitam abordagens nominalistas que negam a realidade e, por conseguinte, os poderes causais de estruturas sociais, tomando-as como meras "abstrações" convenientes para designar uma infinidade de padrões de ação e interação. Argumentos similares poderiam ser desenvolvidos no que tange aos demais postulados praxiológicos delineados anteriormente.

\section{Conclusão: questões remanescentes}

Ao emprestar um papel de proa às praxiologias "estruturacionistas" de Giddens e Bourdieu na minha exposição da virada praxiológica, certamente não parto da premissa de que ambos teriam sido plenamente bem-sucedidos em seus esforços de síntese teórica. A despeito de sua riqueza heurística, a tentativa bourdieusiana de superação da dicotomia objetivismo/ /subjetivismo, por exemplo, tende a resultar em um "neo-objetivismo" que, 
por devotar atenção insuficiente à reflexividade dos agentes leigos, submete a noção de habitus a uma sobrecarga de trabalho analítico (Peters, 2013). Ademais, segundo o que se depreende das críticas à praxiologia estrutural de Bourdieu na sociologia francesa pós-bourdieusiana (Vandenberghe, 2010: 85-110), alguns autores julgam não apenas que o veio "estrutural" tende, por vezes, a sobrepujar o veio "praxiológico" em sua teoria, mas também, mais radicalmente, que o próprio conceito de "estrutura" seria insuficientemente praxiológico e processual, devendo ser substituído por noções como "associação" ou "rizoma" (ibidem: 123-146). Com efeito, entre teorias que se pretendem praxiológicas e relacionais, o mais significativo divisor de águas parece ser, hoje, aquele que separa ontologias planas e ontologias estratifcadas da vida social. Deve o exame sociológico da vida societária apreender as conexões causais entre seus diferentes níveis (e.g., o nível micro das interações face a face, o nível meso das instituições e o nível macro dos sistemas de posições objetivas)? Ou deve a análise do mundo social seguir a trama histórica das associações mutáveis e heterogêneas pelas quais tal mundo se faz, se desfaz e se refaz em uma multiplicidade de cenários, sem que seja jamais necessário "pular" de um nível ontológico para outro? A oposição entre o relacionismo estrutural de Bourdieu e a "associologia" nominalista de Latour na teoria social francesa é uma ilustração radical, mas certamente não a única, desse conflito entre ontologias estratificadas e planas.

Finalmente, como já antecipado pela referência ao problema da reflexividade do agente leigo na sociologia de Bourdieu, outra das questões mais controversas no tocante ao legado da praxiologia consiste na sua tendência a privilegiar cenários heurísticos de "rotina" (Giddens) ou "cumplicidade ontológica" (Bourdieu) entre as dimensões subjetiva e objetiva do universo social. Quando as demandas práticas dos ambientes sociais em que operam os agentes correspondem significativamente às suas orientações subjetivas de conduta, aqueles ambientes são subjetivamente vivenciados como naturais e autoevidentes. Nesses cenários, as competências habituais do "senso prático" tendem a operar como os principais motores subjetivos da ação social. Em contraste com essa heurística da cumplicidade ontológica, muita da sociologia francesa pós-bourdieusiana se desenvolveu mediante uma heurística de "momentos críticos" (Boltanski e Thévenot, 1991) e "situações problemáticas" (Cefaï, 2009). Enquanto Bourdieu privilegiou cenários de cumplicidade ontológica entre disposições subjetivas e condições objetivas, teorizando "efeitos de histerese" (1983: 64) como desvios daquele modelo, seus críticos de inspiração pragmatista e/ou pragmática fazem o inverso, tomando contextos de desajuste entre umas e outras como loci heuristicamente privilegiados para a apreensão dos processos constitutivos 
do mundo social, inclusive daqueles contextos não problemáticos em que ele é experimentado como familiar e autoevidente. A diferença entre as heurísticas mencionadas se desdobra em discrepâncias no tocante aos motores subjetivos da ação social, já que, nos momentos problemáticos em que a orquestração das disposições habituais é insuficiente para garantir a coordenação das ações no mundo social, tem-se a passagem para uma conduta baseada em deliberações reflexivas que assumem modalidades diversas - e.g., a forma interna de "ensaios imaginativos" (Dewey, 1930) e "conversações interiores" (Archer, 2003) ou a forma externa, dialógica, de críticas e justificações públicas ancoradas em "ordens axiológicas" (Boltanski e Thévenot, 1991), etc. ${ }^{9}$

Juntamente com as controvérsias quanto ao caráter plano ou estratificado da ontologia do social, as questões oriundas dessa interface entre praxiologia, (neo)pragmatismo e sociologia pragmática continuarão, não há dúvida, a alimentar debates fecundos sobre a vida humana em sociedade.

Revisto por Sofia Silva

\section{Referências bibliográficas}

Alexander, Jeffrey C. (1987), "O novo movimento teórico", Revista Brasileira de Ciências Sociais, 2(4), s.p.

Archer, Margaret (2003), Structure, Agency and The Internal Conversation. Cambridge: Cambridge University Press.

\footnotetext{
${ }^{9}$ Uma fertilização recíproca entre a teoria bourdieusiana do habitus, de um lado, e velhas lições pragmatistas de Dewey e Mead sobre a passagem do "hábito" à reflexividade, de outro, me parece fecunda neste ponto. Por um lado, contra uma "dualidade problemática entre criatividade e hábito" (Dalton, 2004: 604), Bourdieu tem razão em sublinhar o caráter versátil, flexível, adaptativo e criativo das disposições habituais. Por outro lado, Bourdieu (2009: 103) desliza ao pressupor, ele próprio, um hiato um tanto radical entre tais disposições habituais e as faculdades reflexivas dos agentes, o que ele faz ao reduzir o exercício eficaz da reflexividade pelos agentes leigos aos cenários de crise radical que chama de "efeito de histerese" - sob esse aspecto, aliás, a visão de Giddens (2003) sobre a "permeabilidade" entre "consciência prática" e "consciência discursiva” é mais satisfatória). Bourdieu deixa, assim, de reconhecer com os pragmatistas que doses relativas de descompasso entre expectativas e habilidades do habitus, de um lado, e injunções objetivas do meio social, de outro, são mais frequentes no mundo social do que o seu esquema teórico se dispunha a admitir. Também mais frequentes e fluidas na conduta societal ordinária são, por conseguinte, as transições entre habitus e reflexividade como motores subjetivos primordiais das práticas humanas. Nesse sentido, infundindo certa sensibilidade pragmatista na teoria da ação de Bourdieu, seria o caso de apontar para "micro-histereses" como parte e parcela da existência social cotidiana: disjunções entre propensões subjetivas de conduta, de um lado, e demandas práticas de ambientes de ação, de outro, cujos graus variam ao longo de um imenso continuum entre os polos extremos da máxima "histerese" ou desajuste, em um lado, e do máximo ajuste ou "cumplicidade ontológica", em outro (Elder-Vass, 2007: 341; Peters, 2017).
} 
Boltanski, Luc; Thévenot, Laurent (1991), De la justification: les économies de la grandeur. Paris: Gallimard.

Bourdieu, Pierre (1983), Sociologia. Organização de Renato Ortiz, Coleção Grandes Cientistas Sociais. São Paulo: Ática. Tradução de Paula Montero e Alícia Auzmendi.

Bourdieu, Pierre (1989), O poder simbólico. Rio de Janeiro: Bertrand Brasil. Tradução de Fernando Tomaz.

Bourdieu, Pierre (1990), Coisas ditas. São Paulo: Brasiliense. Tradução de Cássia R. da Silveira e Denise Moreno Pegorim.

Bourdieu, Pierre (2009), O senso prático. Petrópolis: Vozes. Tradução de Maria Ferreira.

Cefaï, Daniel (2009), “Comment se mobilise-t-on? L'apport d'une approche pragmatiste à la sociologie de l'action collective”, Sociologie et sociétés, 41(2), 245-269.

Cohn, Gabriel (1979), Crítica e resignação: fundamentos da sociologia de Max Weber. São Paulo: T. A. Queiroz.

Dalton, Benjamin (2004), "Creativity, Habit and the Social Products of Creative Action: Revising Joas, Incorporating Bourdieu”, Sociological Theory, 22(4), 602-622.

Dewey, John (1930), Human Nature and Conduct: An Introduction To Social Psychology. New York: Random House.

Elder-Vass, Dave (2007), "Reconciling Archer and Bourdieu in an Emergentist Theory of Action”, Sociological Theory, 25(4), 325-346.

Garfinkel, Harold (1967), Studies in Ethnomethodology. New Jersey: Prentice-Hall.

Giddens, Anthony (1993), New Rules of Sociological Method: A Positive Critique of Interpretive Sociologies. London: Polity Press.

Giddens, Anthony (2003), A constituição da sociedade. São Paulo: Martins Fontes. Tradução de Álvaro Cabral.

Heidegger, Martin (2006), Ser e tempo. Petrópolis: Vozes. Tradução de Márcia Sá Cavalcante Schuback [orig. 2002].

Latour, Bruno (1996), “On Interobjectivity”, Mind, Culture, and Activity, 3(4), 228-245.

Latour, Bruno (2005), Reassembling the Social: An Introduction to Actor-Network Theory. Oxford: Oxford University Press.

Marx, Karl (2000), Manifesto do partido comunista \& teses sobre Feuerbach. São Paulo: Martin Claret.

Mauss, Marcel (2003), Sociologia e antropologia. São Paulo: Cosac \& Naif. Tradução de Paulo Neves.

McLuhan, Marshall (1994), Understanding Media: The Extensions of Man. Cambridge: MIT Press.

Merleau-Ponty, Maurice (2002), Fenomenologia da percepção. São Paulo: Martins Fontes. Tradução de Carlos Alberto Ribeiro de Moura.

Peters, Gabriel (2013), "Habitus, reflexividade e neo-objetivismo na teoria da prática de Pierre Bourdieu”, Revista Brasileira de Ciências Sociais, 28(83), 47-71. 
Peters, Gabriel (2015), Percursos na teoria das práticas sociais: Anthony Giddens e Pierre Bourdieu. São Paulo: Annablume.

Peters, Gabriel (2017), A ordem social como problema psíquico: do existencialismo sociológico à epistemologia insana. São Paulo: Annablume.

Reckwitz, Andreas (2002), "Toward a Theory of Social Practices: A Development in Culturalist Theorizing”, European Journal of Social Theory, 5(2), 243-263.

Ryle, Gilbert (2009), The Concept of Mind. London: Routledge.

Sahlins, Marshall (1999), Ilhas de história. Rio de Janeiro: Jorge Zahar. Tradução de Barbara Sette.

Schatzki, Theodore R. (1996), Social Practices: A Wittgensteinian Approach to Human Activity and the Social. Cambridge: Cambridge University Press.

Schatzki, Theodore R. (1997), "Practices and Actions: A Wittgensteinian Critique of Bourdieu and Giddens", Philosophy of the Social Sciences, 27(3), 283-308.

Schütz, Alfred (1979), Fenomenologia e relações sociais. Rio de Janeiro: Zahar Editora. Tradução de Ângela Melin.

Taylor, Charles (1997), As fontes do self: a construção da identidade moderna. São Paulo: Loyola. Tradução de Adail Ubirajara Sobral e Dinah de Abreu Azevedo.

Taylor, Charles (2005), "Merleau-Ponty and the Epistemological Picture", in Taylor Carman; Mark B. N. Hansen (orgs.), The Cambridge Companion to Merleau-Ponty. Cambridge: Cambridge University Press, 26-49.

Vandenberghe, Frédéric (2010), Teoria social realista. Um diálogo franco-britânico. Belo Horizonte: Editora UFMG. Traduções de Gabriel Peters, Estela Abreu e Ana Liési Thurler.

Wittgenstein, Ludwig (1958), Philosophical Investigations. Oxford: Basil Blackwell.

Artigo recebido a 03.06 .2020

Aprovado para publicação a 21.08.2020

\section{Gabriel Peters}

Programa de Pós-Graduação em Sociologia, Departamento de Sociologia, Universidade Federal de Pernambuco

Av. Prof. Moraes Rego, 1235, Cidade Universitária, CEP: 50670-901 Recife (PE), Brasil

Contacto: gabrielpeters@hotmail.com

ORCID: https://orcid.org/0000-0002-0595-2663 


\section{The Praxeological Turn}

The article examines the "praxeological turn" within the social sciences in the second half of the 20th century, a turn which is manifest in theories that, despite their disagreements over diverse questions, are all anchored in a processual ontology that apprehends the social world as a domain of practices. Focusing on the resemblances rather than on the differences between varied branches of praxeology, the article offers an ideal-typical account of the praxeological turn in social theory. Starting with its philosophical sources in existential phenomenology and in the pragmatics of language, the text deals with seven postulates shared by the praxeological theories of authors, such as Giddens, Garfinkel, Taylor, Bourdieu and Latour. As "internal turns" combined within praxeology, those postulates include the existential, the cultural, the habitual, the bodily, the objectal, the intersubjectivist and the multidimensional turns. Keywords: Anthony Giddens; culturalism; Pierre Bourdieu; praxeology; social theory.

\section{Le tournant praxéologique}

Dans cet article j'examine le «tournant praxéologique » dans les sciences sociales dans la seconde moitié du siècle $\mathrm{xx}^{\mathrm{e}}$, un tournant qui se manifeste dans les théories qui, en dépit de leurs désaccords sur différentes questions, sont toutes ancrées dans une ontologie procédurale qui prend le monde social comme domaine de pratiques. En mettant l'accent sur les similitudes, plutôt que sur les différences, entre les divers aspects de la praxéologie, je présente un tableau idéal-typique du tournant praxéologique dans la théorie sociale. À partir de ses sources philosophiques dans la phénoménologie existentielle et de la pragmatique du langage, j’aborde sept postulats présents, bien que sous des formes différentes, dans les théories praxéologiques d'auteurs comme Giddens, Garfinkel, Taylor, Bourdieu et Latour. En tant que « virages internes » qui se combinent dans la praxéologie, ces postulats incluent les tournants existentiel, culturaliste, habituel, corporel, objectal, intersubjectiviste et multidimensionnel.

Mots-clés: Anthony Giddens; culturalisme; Pierre Bourdieu; praxéologie; théorie sociale. 